\title{
Histomonose em pavão (Pavo cristatus)
}

\section{Histomonosis in peacock (Pavo cristatus)}

\footnotetext{
${ }^{1}$ Centro Universitário Integrado, Campo Mourão, PR, Brasil

2 Universidade Federal do Paraná (UFPR), Palotina, PR, Brasil

${ }^{3}$ Universidade Regional Integrada do Alto Uruguai e das Missões (URI), Santiago, RS, Brasil
}

*Correspondência: gabrielanery28@gmail.com

Submetido: 9 out 2020 | Aprovado: 25 jan 2021

DOI: http://dx.doi.org/10.7213/acad.2021.19201

Rev. Acad. Ciênc. Anim. 2021;19:e19201

\section{Resumo}

O objetivo desse trabalho foi descrever um caso de histomonose em pavão (Pavo cristatus), como também os métodos de diagnóstico e as alterações macroscópicas e histopatológicas características desta doença. Um pavão criado extensivamente em uma propriedade, e em contato com outras aves, foi encaminhado morto ao Laboratório de Patologia Animal do Centro Universitário Integrado, em Campo Mourão, PR. Durante a necropsia, verificou-se que o ceco apresentava serosa com áreas hemorrágicas multifocais e que o fígado exibia leve aumento com áreas levemente pálidas multifocais. Fezes e fragmentos dos órgãos foram coletados e encaminhados para a análise. No exame coproparasitológico verificou-se a presença de ovo de Heterakis gallinarum, hospedeiro paratênico do Histomonas meleagridis. No intestino foram identificadas lesões em forma de placas circulares firmes, com bordas

\author{
Gabriela Nery dos Reis (10 ${ }^{1 *}$ \\ Joana Cristina Smaha de Jesus Lima (iD ${ }^{1,2}$ \\ Thais Lara das Neves Nogueira (i) ${ }^{1}$ \\ Roberta dos Santos Toledo (i) ${ }^{1}$ \\ Monique Togni (i) ${ }^{1,3}$
}

brancacentas e enegrecidas; no fígado, áreas levemente pálidas. $\mathrm{Na}$ análise histopatológica determinou-se hepatite com necrose hepática, necrose e ulceração do ceco, sendo estas lesões características de histomonose.

Palavras-chave: Aves. Cabeça negra. Histomonas. Nematoide.

\section{Abstract}

The objective of this work was to carry out a case report on histomonose in a peacock (Pavo cristatus), as well as describing the methods of diagnosis and macroscopic and histopathological changes characteristic of this disease. A peacock raised extensively on a property, and in contact with other birds, was sent dead to the Animal Pathology Laboratory of the Centro Universitário Integrado, in Campo Mourão, PR. During the necropsy, the cecum was serous with multifocal hemorrhagic areas and the liver showed a slight increase with lightly pale miliary multifocal areas. The stool and fragments of the organs were collected and sent for analysis. Coproparasitological examination detected the presence of Heterakis gallinarum eggs, a paratenic host of Histomonas meleagridis. In the intestine, lesions in the form of firm circular plaques, with white and blackish edges, were identified; and in the liver, slightly pale areas. Histopathological analysis determined hepatitis with hepatic necrosis, necrosis and ulceration of the cecum, lesions characteristic of histomonosis.

Keywords: Birds. Black Head. Histomonas. Nematoid. 


\section{Introdução}

A histomonose, também conhecida como lesão da cabeça negra das aves, é causada por Histomonas meleagridis, um protozoário de mucosas do ceco e do fígado de aves domésticas e selvagens (Trindade et al., 2011). As aves se infectam ao ingerir o ovo infectado do nematódeo Heterakis gallinarum, o qual atua como hospedeiro paratênico do $\mathrm{H}$. meleagridis (Bowman, 2014; Costa et al., 2018). Como as minhocas são hospedeiros paratênicos de $H$. gallinarum, a ingestão deste oligoqueta também colabora para a infecção por $H$. meleagridis (Brito e Fernandes, 2013). A designação "cabeça preta" foi dada pela primeira vez para descrever a doença quando se acreditava que cianose da cabeça e das barbelas era um aspecto característico. Esse sinal, no entanto, não está necessariamente presente e não se restringe à infecção por H. meleagridis (Vicenzi et al., 2016).

A histomonose é mais frequente em perus jovens, com até 14 semanas de idade, e caracteriza-se por lesões necróticas nos cecos e no fígado (Gonçalves et al., 2009). Essas áreas são caracterizadas pela formação de um material multinodular, amareloacastanhado, na luz do ceco, sendo essa tiflite necrótica a principal lesão observada na necropsia (McDougald, 2008). A mortalidade em aves de granja pode chegar a $100 \%$ e o ceco e o fígado podem tornar-se permanentemente fibróticos em aves que se recuperam (Marietto-Gonçalves et al., 2009). O objetivo deste trabalho foi descrever as características patológicas de histomonose em pavão.

\section{Relato de caso}

Foi encaminhado ao Laboratório de Patologia Animal do Centro Universitário Integrado, em Campo Mourão, $\mathrm{PR}$, um pavão adulto morto para a realização do exame de necropsia. $O$ animal era criado extensivamente em uma propriedade, tendo contato com outras aves. Havia histórico de mortalidade na criação, porém sem diagnóstico de causa e sem histórico de vermifugação dos animais.

Na necropsia constatou-se que o ceco apresentava serosa com áreas multifocais hemorrágicas e, após a abertura do órgão, verificou-se conteúdo pastoso avermelhado a enegrecido no lúmen. A mucosa apresentava placas circulares e firmes, com bordas irregulares brancacentas e enegrecidas. O fígado apresentava leve aumento de volume e áreas multifocais levemente pálidas que variavam de $1 \mathrm{~mm}$ a $0,5 \mathrm{~cm}$ de diâmetro. As fezes foram coletadas para exame coproparasitológico e fragmentos do ceco e fígado foram coletados e fixados em formol a 10\%. As amostras foram encaminhadas para análise histopatológica e coradas pelo método de hematoxilina e eosina (HE). $\mathrm{Na}$ pesquisa de ovos e oocistos, realizada pela técnica de Willis-Mollay (1921), foram identificados ovos elipsoides com parede lisa e sem segmentação do conteúdo, compatíveis com ovos de Ascaridia spp e Heterakis spp. (Bowman, 2014; Taylor et al., 2017).

No exame histopatológico, o ceco se caracterizava pela mucosa com necrose difusa e, por vezes, o epitélio remanescente apresentavase hiperplásico, havendo acentuado infiltrado inflamatório transmural no órgão desde a mucosa até a camada muscular externa, composto por heterófilos, linfócitos e macrófagos. Nestas áreas foram observadas estruturas circulares levemente eosinofílicas, circundadas por halo claro, medindo aproximadamente $15 \mu \mathrm{m}$. Em áreas multifocais, os capilares, vênulas e arteríolas apresentavam paredes espessadas por material hialino e preenchimento por células inflamatórias e hemácias, com oclusão do lúmen vascular. No fígado, observaram-se hepatócitos com vacuolização intracitoplasmática, infiltrado inflamatório multifocal acentuado, semelhante ao descrito no ceco, além de ocasionais células gigantes. As lesões vasculares observadas no ceco também foram evidenciadas no fígado.

Nos exames de necropsia e histopatologia foi observada a estrutura parasitária do Histomonas meleagridis e encontradas alterações no ceco e no fígado compatíveis com histomonose, confirmando a histomonose como causa mortis.

\section{Discussão}

Apesar dos poucos relatos de H. meleagridis em pavões no Brasil, os criadores precisam estar atentos para a presença desta parasitose principalmente em aves jovens e criadas em consórcio com outras aves galináceas, uma vez que a histomonose é considerada uma das causas de mortalidade em pavões (Costa et al., 2018). 
Para que ocorra a infecção, os protozoários precisam de $H$. gallinarum, que age como um hospedeiro paratênico, assim servindo como proteção contra ambientes desfavoráveis à sobrevivência do protozoário (McDougald, 2008). A infecção ocorre após a ingestão dos ovos do nematódeo, presente em excremento de aves portadoras ou nos tecidos de minhocas (Dolka et al., 2015; Hess et al., 2015). No ceco da ave, os ovos de $\mathrm{H}$. gallinarum liberam os trofozoítos de $\mathrm{H}$. meleagridis, que penetram na parede do ceco e perdem seu flagelo. Em seguida, evoluem para o estágio amebóide, o qual, por via hematógena, dissemina-se para o fígado, causando as alterações hepáticas características da doença, como hepatite necrótica (Hauck e Hafez, 2013). Acredta-se que essa rota foi de grande importância para a infecção da ave do presente relato.

$\mathrm{Na}$ análise histopatológica, constatou-se tiflite necrosante difusa acentuada associada à hiperplasia multifocal acentuada, necrose de coagulação e estruturas parasitárias compatíveis com $H$. meleagridis. Identificou-se hepatite difusa moderada associada à degeneração gordurosa, necrose de coagulação e estruturas parasitárias compatíveis com H. meleagridis, similares aos achados na literatura (Vicenzi et al., 2016).

As lesões encontradas nos vasos sanguíneos do ceco e fígado provavelmente são causadas pela fase de migração que o parasita realiza para o fígado após a reprodução, sendo essa migração por via hematógena. O parasita, entretanto, continua reproduzindo-se, dando origem a pontos multifocais de necrose hepática, característica desta enfermidade e observada no pavão deste estudo (Silva et al, 2014).

Taylor et al. (2010) descrevem que as lesões causadas por histomonose são predominantes no ceco e no fígado, podendo haver danos em um ou ambos os cecos com o aparecimento de pequenas úlceras salientes do tamanho da cabeça de um alfinete, que posteriormente podem evoluir e aumentar de tamanho, uma vez que o parasita é capaz de danificar toda a extensão da mucosa, causando ulceração, perfuração da parede cecal e, consequentemente, peritonite. A mucosa se transfigura em espessa e necrótica, podendo apresentar exsudato amarelado e pútrido característico e centros cecais secos e duros aderentes à parede cecal. Geralmente, os cecos estão inflamados e aumentados.

As lesões hepáticas encontradas são patognomônicas e apresentam áreas amareladas circulares com necrose e degeneração tecidual, que variam de tamanho até $1 \mathrm{~cm}$ ou mais e que se aprofundam no fígado. Em aves mais velhas, as lesões podem ser coalescentes, inclusive com acometimento de outros órgãos, como rins ou pulmões. Os parasitas podem ser encontrados por meio de exame histopatológico e as lesões são hiperêmicas, hemorrágicas e, necróticas, com a presença de infiltrado de linfócitos, macrófagos e células gigantes (Taylor et al., 2010).

Para tratamento da doença, indica-se o uso de nitroimidazóis, entretanto, é necessário a prevenção da enfermidade evitando a criação de animais dessa espécie em consórcio com outras da espécie galinácea, tendo a criação por espécies separadas. Recomenda-se trocar os animais de ambiente, evitar a introdução de novas aves na criação e evitar a contaminação por fezes, realizando a limpeza e higienização de comedouros e bebedouros. Além disso, a vermifugação dos animais é imprescindível (Silva et al., 2014).

\section{Conclusão}

Conclui que as lesões encontradas no pavão, caracterizadas por hepatite, necrose hepática e lesões como inflamação, necrose e ulceração do ceco, são características de histomonose. Os exames coproparasitológico, necropsia e histopatológico podem ser utilizados no diagnóstico definitivo e, assim, auxiliar na prevenção de novas infecções.

\section{Referências}

Bowman DD. Parasitologia Veterinária de Georgis. 10 ed. Baureri: Manole; 2014.

Brito DRB, Fernandes RM. Ação anti-helmíntica de Morinda citrifolia (noni) sobre Heterakis gallinarum. Semina: Cienc Agrar. 2013;34(4):1775-82.

Costa RA, Pereira APM, Silveira CS, Anjos BL. Infecção natural por Histomomonas meleagridis em Pavões-Indianos. Acta Sci Vet. 2018;46(Suppl 1):333. 
Dolka B, Zbikowski A, Dolka I, Szeleszczuk P. Histomonosis - an existing problem in chicken flocks in Poland. Vet Res Commun. 2015;39(3):189-95.

Hauck R, Hafez MH. Experimental infections with the protozoan parasite Histomonas meleagridis: a review. Parasitol Res. 2013; 112(1):19-34.

Hess M, Liebhart D, Bilic I, Ganas P. Histomonas meleagridis New insights into an old pathogen. Vet Parasitol. 2015;208 (1-2):67-76.

Marietto-Gonçalves GA, Martins TF, Lima ET, Lopes RS, Andreatti Filho RL. Prevalência de endoparasitas em amostras fecais de aves silvestres e exóticas examinadas no Laboratório de Enfermidades Parasitárias da FMVZ-UNESP/Botucatu, SP. Cienc Anim Bras. 2009;10(1):349-54.

McDougald LR. Histomoniasis (Blackhead) and other Protozoan of the ntestinal Tract. In: Saif YM, editor. Diseases of Poultry. 12 th ed. Ames: Blackwell; 2008. p.1067-221.
Silva TM, Okamoto AS, Smaniotto BD, Paes AC, Andreatti Filho RL. Histomoníase em peru (Meleagris gallopavo) - Relato de caso. Vet e Zootec. 2014;21(12):269-74.

Taylor MA, Coop RL, Wall RL. Parasitologia Veterinária. 3ed. Rio de janeiro: Guanabara Koogan; 2010.

Taylor MA, Coop RL, Wall RL. Parasitologia Veterinária. 4 ed. Rio de Janeiro: Guanabara Koogan; 2017.

Trindade MM, Scheneiders GH, Corrêa IMO, Flores M, Lovato $\mathrm{M}$, Kommers GD. Histomoníase em pavão (Pavo cristatus). Hora Vet. 2011;31(184):56-8.

Vicenzi A, Zoppei AP, Prado JKM, Medeiros JM, Bresolin F, Catarina $A S$, et al. Histomonose em pavão: Relato de caso. Anais do SEPE. 2016;6(1).

Willis $\mathrm{HH}$. A simple levitation method for detection of hookworm ova. Med J Aust. 1921;8:375-6. 